САВРУЦКАЯ Елизавета Петровна - доктор философских наук, профессор; профессор кафедры философии, социологии и теории социальной коммуникации Нижегородского государственного лингвистического университета им. Н.А. Добролюбова (603155, Россия, г. Нижний Новгород, ул. Минина, 31a; savrutsk@mail.ru)

УСТИНКИН Сергей Васильевич - доктор исторических наук, профессор; декан факультета международных отношений, экономики и управления, профессор кафедры международных отношений и политологии Нижегородского государственного лингвистического университета им. Н.А. Добролюбова (603155, Россия, г. Нижний Новгород, ул. Минина, 31а); директор Приволжсккого филиала ФНИСЦ РАН (603000, Россия, г. Нижний Новгород, Холодный пер., 4; sv.ustinkin@gmail.com)

СЕМЕНОВ Дмитрий Владимирович - кандидат философских наук, доцент; доцент кафедры философии, социологии и теории социальной коммуникации Нижегородского государственного лингвистического университета им. Н.А. Добролюбова (603155, Россия, г. Нижний Новгород, ул. Минина, 31a; ds 7771bk.ru)

\title{
ВЛИЯНИЕ СЕМЬИ И ИНСТИТУТОВ ОБРАЗОВАНИЯ НА ФОРМИРОВАНИЕ ЦЕННОСТНОГО СОЗНАНИЯ МОЛОДЕЖИ
}

Аннотация. В статье рассматриваются некоторые актуальные проблемы влияния семьи и институтов образования на формирование ценностных ориентаций молодежи. В контексте стратегии национальной безопасности РФ анализируются особенности динамики оценочного отношения обучающейся молодежи, формирующегося в новых условиях цивилизационного развития общества. Эти условия определяются процессами глобализации, новыми информационно-коммуникативными технологиями, виртуализацией современного коммуникативного пространства.

Ключевые слова: система образования, семья, национальная безопасность, глобализация, информационно-коммуникативные технологии, ценностное сознание, ценностные ориентации, молодежь, виртуальная реальность

П роблемы семейного и общественного воспитания подрастающих поколений всегда были в той или иной степени в центре внимания научных, религиозных и философских исследований. Не потеряли они своей актуальности и в настоящее время. Углубляющиеся противоречия современной коммуникативной ситуации в условиях глобализации и формирования нового мирового порядка концентрируют внимание общественной мысли на проблемах человека, историко-культурной преемственности, гражданской и национальнокультурной идентичности. Особая актуальность исследования этих проблем объясняется динамикой определяющих признаков социальной реальности, увеличения объема знаний, освоение которых затруднено их количеством и совершенно новыми направлениями их практического использования. Кроме того, виртуализация коммуникативного пространства современной цивилизации заставляет по-новому осмысливать происходящие изменения социокультурной реальности; в первую очередь это касается причин и особенностей социальной и духовной неустойчивости, возникающей в процессе перехода к новому миропорядку. В современных условиях особенности развития общественных процессов связаны не только с глобальными преобразованиями и кризисами историко-культурного развития современной цивилизации и напряженностью в сфере международных отношений, но и с недостаточной изученностью общего состояния социокультурных процессов наступающего постглобализационного периода. Анализируя основные особенности цивилизационного развития со- 
временной России и последствия их воздействия на человека под углом зрения национальной безопасности, следует обратить внимание, с одной стороны, на положительные тенденции в развитии современной российской цивилизации, что достаточно подробно зафиксировано в Стратегии национальной безопасности Российской Федерации до 2020 года 1 . В документе, в частности, говорится, что страна устояла перед напором угроз потери суверенитета и территориальной целостности, восстановила возможности наращивания своей конкурентоспособности и отстаивания национальных интересов. Страна успешно осуществляет возрождение исконно российских идеалов, духовности, формируется достойное отношение к исторической памяти, сохраняется уважение к семейным традициям, укрепляется дух патриотизма и общественное согласие на основе общих ценностей.

Вместе с тем в проблемном поле современного этапа цивилизационного развития общества существует ряд показателей, свидетельствующих о необходимости усиления внимания к такой проблеме национальной безопасности страны, как исследование факторов влияния на процессы формирования ценностных ориентаций молодого поколения. В данном случае мы имеем в виду, во-первых, последствия кризиса 1990-х гг., повлекшие за собой технологическое отставание России, а также трансформацию ценностей и приоритетов массового молодежного сознания, формирующегося под влиянием современной массовой культуры, цивилизационных изменений и политических процессов в мире в целом и в России в частности, размывание границ гражданской и этнокультурной идентичности.

Во-вторых, специфически российские социокультурные процессы происходят в условиях коренных изменений общецивилизационного порядка, таких как информационная переизбыточность, «коммуникативная революция», глобализация, мощнейший импульс в распространении глобальной системы Интернет, маргинализация культуры, увеличение числа форм и направлений институциональной аномии, распространение деструктивных религиозных движений, усиливающих тенденцию расширения видов девиантного поведения.

В-третьих, ослабление роли семьи и семейного воспитания в реализации процесса духовно-нравственной преемственности и формировании ценностного сознания подрастающих поколений поставило молодежь лицом к лицу с проблемой собственного выбора ценностных ориентаций и жизненных установок, т.к. зачастую она не имела возможности опереться на социокультурный опыт старших поколений. Не всегда удачные попытки модернизации образования и трансформация системы культурных кодов явились причиной критического ослабления нравственно-нормативной регуляции поведения и сохранения оснований этнокультурной и гражданской идентичности.

При рассмотрении этих особенностей под углом зрения национальной безопасности становится очевидной необходимость исследования определяющих факторов современной социокультурной среды на формирование ценностного сознания и мотивацию поведения молодежи. В качестве эмпирической базы этого исследования мы прежде всего выбрали результаты научно-исследовательского проекта «Динамика ценностных ориентаций молодежи», осуществляемого ведущими учеными Нижегородского государственного лингвистического университета на протяжении 10 лет - с 2006 по 2016 г. Объектом исследования явились учащиеся старших классов средних общеобразовательных школ г. Нижнего Новгорода и Нижегородской обл., а также техни-

\footnotetext{
1 Стратегия национальной безопасности Российской Федерации до 2020. Утв. Указом Президента РФ от 12.05.2009 № 537. Разд. 5, ст. 68. Доступ: http://www.garant.ru/products/ipo/prime/doc/95521/
} 
кумов и колледжей Нижнего Новгорода и районных центров Нижегородской обл., студенты высших учебных заведений Нижнего Новгорода, Арзамаса, Дзержинска. Число респондентов составило: в 2006 г. - 1900 чел., в 2011 г. - 3000 чел., в 2014 г. - 2500 чел., в 2015 г. - 2500 чел., в 2016 г. - 2750 чел. Результаты проведенных опросов носят репрезентативный характер и объективно отражают динамику ценностных ориентаций молодежи Нижнего Новгорода и Нижегородской обл.

Сравнительный анализ результатов опросов позволил выявить приоритеты ценностного сознания учащейся молодежи в определении иерархии факторов влияния на формирование ее политических и экономических установок (см. табл. 1). Приведенные в таблице данные результатов исследований наглядно свидетельствуют, что влияние семьи и школы (имеется в виду система образования в целом) на формирование политических и экономических установок массового сознания обучающейся молодежи хотя и уступает по значимости влиянию новых медиа, но сохраняет свои приоритетные позиции относительно других субъектов коммуникации, представляя собой достаточно устойчивый канал социального воздействия на духовно-нравственные процессы, политические и экономические установки.

Таблица 1

Факторы влияния на политические и экономические установки молодежи, \%

\begin{tabular}{|c|c|c|c|c|}
\hline Годы & Интернет и СМИ & Родители & $\begin{array}{c}\text { Институты } \\
\text { образования }\end{array}$ & Друзья \\
\hline 2006 & 72,3 & 33,0 & 20,4 & 13,0 \\
\hline 2011 & 63,3 & 34,5 & 16,9 & 23,2 \\
\hline 2014 & 70,2 & 33,2 & 21,6 & 18,4 \\
\hline 2015 & 70,8 & 45,3 & 35,0 & 26,4 \\
\hline 2016 & 76,0 & 40,4 & 35,1 & 26,8 \\
\hline
\end{tabular}

По шкале показателей влияния видно, что 2-е место в иерархии факторов социальной среды, оказывающих наибольшее влияние на формирование ценностных установок молодежи, хотя и с заметным отставанием от СМИ и Интернета, занимает семья. Однако эти же данные свидетельствуют и о том, что, несмотря на сохранение влияния родителей на ценностные ориентации молодежи, оно вместе с тем не является приоритетным. Этот факт в определенной степени затрудняет формирование у молодых россиян четких политических и экономических ориентаций, а также устойчивых стратегий реального ценностного выбора в соответствующих сферах, что создает значительные трудности в воспитании подрастающего поколения в соответствии с установками национальной безопасности страны.

Данные исследований особенностей ценностных ориентаций молодежи, проведенных в НГЛУ в рамках проекта «Динамика ценностных ориентаций молодежи (2006-2016)», свидетельствуют о существовании ряда проблем, снижающих роль семьи в формировании политических ориентиров и экономических установок молодежи. Данная тенденция подтверждается и оценкой респондентами различных возрастных групп и типов учебных заведений помощи родителей в понимании молодежью сложных проблем экономического и политического характера (см. табл. 2 и 3 ).

Анализируя данные качественных и количественных изменений ценностного 
сознания молодежи в ее оценке роли родителей в формировании политических и экономических установок, необходимо особо отметить достаточно устойчивую положительную динамику этих процессов.

Таблица 2

Роль родителей в формировании политических установок молодежи, \%

\begin{tabular}{|c|l|c|c|c|c|c|}
\hline \multicolumn{1}{|c|}{ Утверждение } & \multicolumn{1}{|c|}{ Вариант ответа } & $\mathbf{2 0 0 6}$ & $\mathbf{2 0 1 1}$ & $\mathbf{2 0 1 4}$ & $\mathbf{2 0 1 5}$ & $\mathbf{2 0 1 6}$ \\
\hline \multirow{4}{*}{$\begin{array}{l}\text { Мои родители } \\
\text { очень помогают }\end{array}$} & Полностью согласны & 13,4 & 11,6 & 12,3 & 18,9 & 15,2 \\
\cline { 2 - 7 } $\begin{array}{l}\text { мне разобраться } \\
\text { в политических }\end{array}$ & Скорее согласны & 19,6 & 22,9 & 21,0 & 26,4 & 25,2 \\
\cline { 2 - 7 } & Затруднились ответить & 14,7 & 21,8 & 22,1 & $17,3$. & 21,1 \\
\cline { 2 - 7 } & Скорее не согласны & 25,3 & 24,7 & 23,6 & 20.3 & 18,4 \\
\cline { 2 - 7 } & Не согласны & 27,0 & 19,0 & 21,0 & 16,4 & 20,1 \\
\hline
\end{tabular}

Так, по данным исследования 2016 г. с утверждением «мои родители помогают мне разобраться в политических событиях» выразили полное согласие 15,2\% молодых нижегородцев и жителей области (в 2006 г. такой ответ дали 13,4\% участников опроса). С учетом тех, кто «скорее согласен» с этим высказыванием, позитивное отношение к нему проявили около трети респондентов (в 2006 г. $-33 \%$, в 2011 г. $-34,5 \%$, в 2014 г. $-33,2 \%$, в 2015 г. - 45,3\%, в 2016 г. - 40,4\%). Общее число молодых людей, отрицающих влияние родителей на их политические взгляды, в 2006 г. составило более половины (52,3\%); но в 2016 г. число отрицательных ответов по данному пункту сократилось до 42,6\%.

Таблица 3

Роль родителей в формировании экономических установок молодежи, \%

\begin{tabular}{|c|c|c|c|c|c|c|}
\hline Утверждение & Вариант ответа & 2006 & 2011 & 2014 & 2015 & 2016 \\
\hline \multirow{5}{*}{$\begin{array}{l}\text { Мои родители } \\
\text { очень помогают } \\
\text { мне разобраться } \\
\text { в событиях } \\
\text { экономической } \\
\text { жизни }\end{array}$} & Полностью согласны & 11,4 & 10,9 & 9,5 & 14,9 & 12,9 \\
\hline & Скорее согласны & 21,1 & 24,8 & 22,5 & 27,4 & 26,4 \\
\hline & Затруднились ответить & 16,5 & 23,3 & 22,3 & 21,0 & 20,4 \\
\hline & Скорее не согласны & 25,1 & 22,6 & 24,0 & 20,7 & 19,4 \\
\hline & Не согласны & 25,9 & 18,4 & 21,8 & 16,0 & 23,2 \\
\hline
\end{tabular}

Близкими к данным по политическим вопросам являются данные по оценке влияния родителей на формирование ценностного сознания молодежи в ее отношении к проблемам экономики (см. табл. 3). По этой причине мы не проводим специальный анализ в данном контексте.

Вместе с тем обращаем внимание на следующие два момента, привлекающие к себе особое внимание. Во-первых, это увеличение числа тех респондентов, которые затруднились с ответом: если в 2006 г. затруднения в ответе на данный вопрос анкеты испытывали 14,7\% опрошенных, то в 2016 г. число сомневающихся в своем отношении к рассматриваемой проблеме увеличилось до $21,1 \%$. Во-вторых, наибольшее неприятие родительской помощи в понимании политических и экономических вопросов оказалось у той части молодежи, которая нигде не учится $(68,9 \%)$, затем по убывающей идут учащиеся техникумов и 
колледжей (45,5\%), с небольшим отрывом от них - студенты вузов (41,6\%). В наименьшей степени отказываются принимать эту помощь учащиеся средних школ, показатель которых оказался равным 38,7\%.

Важным с точки зрения степени влияния родительского авторитета на ценностное сознание обучающейся молодежи, оказания помощи в понимании детьми политических событий и экономических процессов является показатель регулярности общения молодых людей с родителями (см. табл. 4).

Таблица 4

Роль родителей в формировании политических установок молодежи, \%

\begin{tabular}{|c|l|c|c|c|c|c|}
\hline \multicolumn{1}{|c|}{ Утверждение } & \multicolumn{1}{|c|}{ Вариант ответа } & $\mathbf{2 0 0 6}$ & $\mathbf{2 0 1 1}$ & $\mathbf{2 0 1 4}$ & $\mathbf{2 0 1 5}$ & $\mathbf{2 0 1 6}$ \\
\hline \multirow{2}{*}{$\begin{array}{l}\text { Мы с родителями } \\
\text { часто } \\
\text { разговариваем } \\
\begin{array}{l}\text { о политике и } \\
\text { важных вопросах } \\
\text { нашей страны }\end{array}\end{array}$} & Полностью согласны & 8,7 & 9,5 & 9,5 & 12,5 & 10,8 \\
\cline { 2 - 7 } & Скорее согласны & 19,7 & 25,1 & 19,3 & 24,8 & 22,6 \\
\cline { 2 - 7 } & Затруднились ответить & 8,8 & 16,2 & 14,3 & 17,2 & 17,8 \\
\cline { 2 - 7 } & Скорее не согласны & 26,3 & 25,1 & 26,9 & 21,6 & 22,6 \\
\cline { 2 - 7 } & Не согласны & 36,5 & 24,2 & 29,9 & 22,9 & 26,2 \\
\hline
\end{tabular}

Таблица 5

Роль родителей в формировании экономических установок молодежи, \%

\begin{tabular}{|c|c|c|c|c|c|c|}
\hline Утверждение & Вариант ответа & 2006 & 2011 & 2014 & 2015 & 2016 \\
\hline \multirow{5}{*}{$\begin{array}{l}\text { Мы с родителями } \\
\text { часто } \\
\text { разговариваем на } \\
\text { экономические } \\
\text { темы }\end{array}$} & Полностью согласны & 8,6 & 7,5 & 6,8 & 9,4 & 8,7 \\
\hline & Скорее согласны & 16,9 & 22,7 & 15,8 & 18,6 & 20,4 \\
\hline & Затруднились ответить & 13,9 & 18,2 & 19,1 & 21,5 & 21,0 \\
\hline & Скорее не согласны & 28,1 & 27,9 & 29,1 & 26,7 & 24,2 \\
\hline & Не согласны & 32,4 & 23,7 & 29,1 & 22,8 & 25,6 \\
\hline
\end{tabular}

Как видно из данных, приведенных в табл. 4 и 5, частота общения родителей и детей достаточно низка, несмотря на некоторое увеличение положительных показателей взаимодействия «отцов» и «детей».

Регулярное взаимодействие родителей и детей в обсуждении жизненно важных вопросов политического и экономического характера в целом признают не более 28-30\% опрошенных, в то время как число респондентов, отрицающих это, в целом заметно сократившись за 10 лет более чем на $10 \%$ (60,5\% в 2006 г. и 49,80\% в 2016 г.), в 1,5 раза превышает положительные показатели.

Рассмотрение данной особенности, характерной для нашего времени, в определенной степени свидетельствует о ценностном кризисе. Оценивая это явление под углом зрения национальной безопасности, следует признать, что системная трансформация российского общества 90-Х гг. ХХ в. обусловила коренную ломку его ценностной основы, затронувшую ценностное сознание не только молодежи, но и старших поколений, что не могло не отразиться на показателях авторитета семьи в оценках «детей», на неоднозначном отношении младшего поколения к старшему. Но и в отношениях старшего поколения к детям, как отмечает Д.И. Фельдштейн, можно обнаружить безразличие, от- 
сутствие потребности в покровительстве, равнодушие, забвение «ответственности взрослого общества за детей» и утрату «причастности Взрослого Мира к Детству». Реально взрослое общество «отстранилось от Детства - нет устойчивой иерархии разнообразных связей, системного взаимодействия», что существенно усложняет функционирование механизмов социальной преемственности [Фельдштейн 2013].

В исследовании проблемы «семья - дети» в современных условиях первой четверти XXI в. все большую актуальность приобретает вопрос о влиянии новыХ информационно-коммуникативных технологий и виртуальной коммуникации на формирование ценностного мировосприятия молодежи. Очевидно, что в условиях, отягченных расширением виртуального мира, роль родителей и семейных отношений в целом в воспитании детей все более усложняется. В известном исследовании «Новый цифровой мир. Как технологии меняют жизнь людей, модели бизнеса и понятие государства» председателя совета директоров компании Google Э. Шмидта и директора Google ideas Д. Коэна проблема отношений «родители - дети» включена в разряд социальных явлений, в наибольшей степени подверженных влиянию новых цифровых технологий. В рассматриваемом контексте авторы выделяют два момента, которые усложняют роль родителей в воспитании своих детей. Первую линию размышлений авторов по рассматриваемому кругу вопросов мы отнесли к сознательному управлению «своими онлайнличностями и виртуальными жизнями, ...чтобы не усложнять свою жизнь... с самого раннего возраста» [Шмидт, Коэн 2013]. Но это невозможно, т.к. у детей и подростков желание делиться информацией о себе всегда берет верх над осознанием возможности вытекающих негативных последствий подобной информационной открытости и формирующейся потребности в постоянном присутствии в социальных сетях. Как признают Д. Коэн и Э. Шмидт, к 40 годам в сети сложится подробное повествование о жизни человека. И эта информация, включающая и вымыслы, и ошибки, и даже слухи, будет жить вечно, она может быть использована для разрушения репутации человека, связывая вымышленные или вырванные из контента онлайн-личности факты, которые могут быть рассмотрены под углом зрения реального или вымышленного преступления. Это не физическое насилие, это виртуальное насилие над репутацией личности, его жизненными планами и ценностями.

Какова же роль родителей в решении этой сложнейшей проблемы современности? По мнению некоторых исследователей, установление доверительной коммуникации между родителями и детьми является важнейшим моментом в решении данной проблемы. Поскольку, как отмечают авторы, «виртуальное развитие детей значительно опережает их физическое созревание, большинство родителей придут к пониманию того, что самый лучший способ помочь своим отпрыскам - поговорить с ними», т.к. «традиционный разговор с детьми по душам не утратит своей роли в их воспитании» [Савруцкая и др. 2017].

В свете Стратегии национальной безопасности РФ для решения проблемы сохранения семейных ценностей, повышения роли семьи в воспитании подрастающих поколений большое значение имеет реализация разрабатываемого проекта «Крепкая семья - крепкая Россия». Целью проекта является укрепление института семьи и семейных ценностей; всестороннее социальное развитие личности и патриотическое воспитание через институт семьи; формирование общественного мнения о высокой значимости семьи и семейного воспитания и т.д. ${ }^{1}$ Объявление указом Президента РФ 2018-2027 гг. Десятилетием детства

\footnotetext{
1 Стратегия национальной безопасности Российской Федерации до 2020. Утв. Указом Президента РФ от 12.05.2009 № 537. Разд. 1, ст. 1.
} 
предполагает решение многих вопросов по улучшению семейного воспитания в стране, решению демографической ситуации, созданию условий безопасного детства и многое другое.

Подводя итоги сказанного выше, хотелось бы отметить, что в ряду проблем, связанных с воспитанием подрастающих поколений и сохранением историкокультурной преемственности, по социальной и духовной значимости приоритетная роль принадлежит семье как важнейшему социальному институту сохранения социально значимых ценностей. В изменениях ценностных ориентаций молодежи, вызванных глубокими трансформациями цивилизационных процессов современности, важную роль играет отношение молодых поколений к социальному опыту «отцов». Реальные связи детей и родителей выражаются в принятии молодыми людьми ценностного наследия старших поколений или отказе от него. Поэтому конструирование социальной реальности XXI в., образ мира ближайшего будущего в умонастроениях молодежи будет зависеть от ценностного выбора новых поколений. Очевидно, что новые ценностные ориентиры в ходе современной истории заставляют обратиться к проблеме важнейшей роли семьи в сохранении духовной преемственности, т.к. ценностный выбор молодежи определяет перспективы возможного будущего страны. В этой связи необходимость осмысления отношений родителей и детей, изучение динамики влияния родителей на ценностный мир их детей приобретают особую социальную значимость в свете основополагающих требований стратегии национальной безопасности.

Увеличивающаяся роль науки и институтов образования в инновационном развитии общества настоятельно требует повышения уровня образовательной деятельности, выполнения государственного заказа на подготовку высококвалифицированных специалистов и рабочих кадров, проведения системных исследований «в интересах решения стратегических задач национальной обороны, государственной и общественной безопасности, а также устойчивого развития страны» [Фельдштейн 2013]. В этой связи в Стратегии национальной безопасности Российской Федерации до 2020 года в среднесрочной и долгосрочной перспективе определены два направления развития науки, технологий и образования. Во-первых, формирование «системы целевых фундаментальных и прикладных исследований и ее государственной поддержки в интересах организационно-научного обеспечения достижения стратегических национальных приоритетов». Во-вторых, создание сети федеральных национальных исследовательских университетов, «обеспечивающих в рамках кооперационных связей подготовку специалистов для работы в сфере науки и образования, разработки конкурентоспособных технологий и образцов наукоемкой продукции, организации наукоемкого производства» [Шмидт, Коэн 2013: 47].

Однако современные тенденции общественного развития таковы, что институты образования при их государственной поддержке должны играть приоритетную роль в формировании ценностных ориентаций молодежи, в организационно-научном обеспечении достижения стратегических национальных интересов [Шмидт, Коэн 2013: 54], что не находит полноценного подтверждения в оценочном отношении респондентов. И этот момент с точки зрения его социальной значимости настораживает, т.к. повышение уровня общего и профессионального образования населения с целью подготовки кадров высшей квалификации, «способных обеспечить конкурентные преимущества национальной экономики и потребности национальной обороны», является приоритетной задачей государственной политики в области национальной безопасности. 
В условиях глубинных количественных и качественных изменений социальной среды, которые происходят под влиянием резкого усложнения международной обстановки, глобализации, а также информационно-коммуникативных процессов современного этапа цивилизационного развития общества, институты образования в первую очередь должны стать одним из определяющих факторов инновационного развития общества.

Однако объективные условия, порождающие значительные трудности в развитии отечественной системы образования, неоднократные попытки модернизации российской системы образования ослабляют влияние институтов образования на формирование ценностных ориентаций молодежи, что в значительной степени затрудняет формирование у молодых россиян четких политических и экономических ориентаций, устойчивых стратегий реального ценностного выбора. Вместе с тем данные исследования демонстрируют достаточно устойчивую тенденцию улучшения отношения молодежи к институтам образования как фактору влияния на формирование оценочного отношения респондентов к социально значимым проблемам политического и экономического характера (см. табл. 6).

Таблица 6

\section{Влияние институтов образования на формирование ценностного сознания респондентов, \%}

\begin{tabular}{|l|l|c|c|c|c|c|}
\hline \multicolumn{1}{|c|}{ Утверждение } & \multicolumn{1}{|c|}{ Варианты ответа } & $\mathbf{2 0 0 6}$ & $\mathbf{2 0 1 1}$ & $\mathbf{2 0 1 4}$ & $\mathbf{2 0 1 5}$ & $\mathbf{2 0 1 6}$ \\
\hline \multirow{2}{*}{$\begin{array}{l}\text { Школа (вуз, суз) } \\
\text { очень помогает } \\
\text { мне разобраться } \\
\begin{array}{l}\text { в политических } \\
\text { событиях }\end{array}\end{array}$} & Полностью согласны & 5,7 & 3,2 & 6,1 & 11,76 & 12,0 \\
\cline { 2 - 7 } & Скорее согласны & 14,7 & 13,7 & 15,5 & 23,36 & 23,1 \\
\cline { 2 - 7 } & Затруднились ответить & 15,0 & 26,8 & 19,4 & 23,40 & 21,7 \\
\cline { 2 - 7 } & Скорее не согласны & 23,6 & 24,0 & 23,7 & 20,40 & 17,7 \\
\cline { 2 - 7 } & Не согласны & 41,0 & 32,3 & 35,3 & 20,40 & 25,5 \\
\hline
\end{tabular}

Вместе с тем, согласно данным опроса, проведенного в 2016 г., 43,2\% опрошенных по всем видам образовательных учреждений отрицают помощь учебных заведений в понимании проблем политического и экономического характера, что на $8 \%$ превышает число тех, кто эту помощь признает. Для сравнения, в 2014 г. число респондентов, отрицающих помощь институтов образования в понимании политических процессов, составляла 59\%, что на 15,8\% превышало показатель 2016 г. Число же опрошенных, признающих эту помощь, составило $21,6 \%$ в 2014 г. против 25,1\% в 2016 г., т.е. за 2 года увеличилось на 3,5\%.

Динамика ценностных ориентаций молодежи на признание или отрицание роли институтов образования в формировании ценностных ориентаций молодых поколений, несмотря на резко выраженную положительную тенденцию в рассматриваемом контексте, заставляет задуматься о причинах сохранения ценностного негативизма молодежного массового сознания в отношении к учебным заведениям, а также существования значительных различий в ценностных показателях респондентов в зависимости от типа учебных заведений (см. табл. 7 и 8). Так, согласно данным опроса, проведенного в 2014 г. по интересующей нас проблеме, наибольшее число респондентов, отрицающих влияние институтов образования на формирование ценностных ориентаций обучающихся, оказалось характерным для обучающихся в высших учебных заведениях. И этот показатель оказался равным 57,3\% опрошенных. 
Таблица 7

Влияние институтов образования на формирование ценностного сознания обучающейся молодежи в 2014 г., \%

\begin{tabular}{|l|c|c|c|c|c|}
\hline \multirow{2}{*}{$\begin{array}{c}\text { Tип образовательного } \\
\text { учреждения }\end{array}$} & \multicolumn{5}{|c|}{ Школа (вуз, СПУ) очень помогает мне разобраться } \\
\cline { 2 - 6 } & $\begin{array}{c}\text { в политических событиях } \\
\text { согласны }\end{array}$ & $\begin{array}{c}\text { Скорее } \\
\text { согласны }\end{array}$ & $\begin{array}{c}\text { Затруднились } \\
\text { ответить }\end{array}$ & $\begin{array}{c}\text { Скорее не } \\
\text { согласны }\end{array}$ & Не согласны \\
\hline Вуз & 4,0 & 12,0 & 16,7 & 26,1 & 31,2 \\
\hline Средняя школа & 5,7 & 24,6 & 19,1 & 20,8 & 29,8 \\
\hline Техникум, колледж & 9,1 & 16,2 & 23,2 & 21,8 & 29,7 \\
\hline
\end{tabular}

Данные опроса 2016 г. показали значительное улучшение количественных показателей оценочного отношения молодежи к возможностям влияния институтов образования на формирование ее политических ориентаций. Так, отрицательный показатель в оценке студентами вузов роли институтов образования в понимании политических событий сократился на 10,5\%. Данные, приведенные в таблицах, свидетельствуют об улучшении на $6,7 \%$ рассматриваемой ситуации в системе средних профессиональных учебных заведений. И только общеобразовательная школа ухудшила свои показатели в рассматриваемом контексте.

По данным нашего опроса, самая высокая оценка признания реальной помощи, оказываемой обучающимся со стороны педагогов, выявлена в 2006 г. в системе средних профессиональных учебных заведений (почти 40\%). Этот показатель говорит прежде всего о том, что помощь, которую ребята могут получить для понимания сложных политических проблем современности, исходит прежде всего от учебного заведения, в котором они учатся. Высокий показатель оценки помощи молодым людям со стороны преподавателей средних профессиональных учебных заведений в решении политических проблем остается и в показателях опросов, проводимых в 2011, 2014 и 2016 гг., несмотря на значительное снижение рейтинга подобного типа учебных заведений по данному вопросу до $33,3 \%$ в 2016 г.

Таблица 8

Влияние институтов образования на формирование ценностного сознания обучающейся молодежи в 2016 г., \%

\begin{tabular}{|l|c|c|c|c|c|}
\hline \multirow{2}{*}{$\begin{array}{c}\text { Tип образовательного } \\
\text { учреждения }\end{array}$} & \multicolumn{5}{|c|}{ Школа (вуз, СПУ) очень помогает мне разобраться } \\
\cline { 2 - 6 } & $\begin{array}{c}\text { В политических событиях } \\
\text { согласны }\end{array}$ & $\begin{array}{c}\text { Скореe } \\
\text { согласны }\end{array}$ & $\begin{array}{c}\text { Затруднились } \\
\text { ответить }\end{array}$ & $\begin{array}{c}\text { Скорее не } \\
\text { согласны }\end{array}$ & Не согласны \\
\hline Вуз & 11,7 & 21,0 & 20,5 & 28,0 & 18,8 \\
\hline Средняя школа & 8,4 & 17,1 & 18,4 & 23,1 & 33,1 \\
\hline Техникум, колледж & 10,5 & 22,8 & 21,8 & 18,6 & 26,2 \\
\hline
\end{tabular}

Оценивая результаты проведенных с 2006 по 2016 гг. исследований под углом зрения национальной безопасности, следует признать, что молодежь, обучающаяся в средних профессиональных учебных заведениях, требует к себе значи- 
тельно большего внимания со стороны общества, образовательных учреждений и политиков. Во-первых, юноши, обучающиеся в системе средних профессиональных учебных заведений, - это основной контингент призывников в ряды российских вооруженных сил, что, естественно, предполагает достаточно большой объем знаний, умений и навыков в обращении с современной военной техникой, их подготовленность к пониманию политических событий, оценку их значения для своей страны. Во-вторых, тенденции развития российского общества таковы, что страна начала остро испытывать недостаток в квалифицированных молодых кадрах среднего звена, т. е. в работниках со средним профессиональным образованием. Очевидно, высокая трудовая результативность в сфере производства возможна прежде всего там, где работник осознает не только материальную ценность своих умственных и физических затрат на производстве. Для него важным стимулом высокопроизводительного труда является понимание социальной значимости затраченных усилий, отношение к стране, в которой он живет, уважение к ее историко-культурным корням, т.е. проявляется в гражданской активности подрастающего поколения ${ }^{1}$.

\section{Список литературы}

Савруцкая Е.П., Жигалев Б.А., Викулина М.А., Макшанцева Н.В. 2017. Институты образования и молодежь: на пути устойчивого развития общества: монография (под общ. ред. Е.П. Савруцкой). Н. Новгород: Изд-во НГЛУ. 184 с.

Фельдштейн Д. 2013. Функциональная нагрузка Академии образования в определении принципов и условий развития растущего человека на исторически новом уровне движения общества: доклад на общем собрании РАО 29 октября 2013 г. - Проблемы современного образования. № 5. С. 6-20. Доступ: http:// www.pmedu.ru (проверено 10.11.2018).

Шмидт Э., Коэн Д. 2013. Новый цифровой мир. Как технологии меняют жсизь людей, модели бизнеса и понятие государства. М.: Манн, Иванов и Фербер. 368 с.

SAVRUTSKAYA Elisaveta Petrovna, Dr.Sci.(Philos.), Professor; Professor of the Chair of Philosophy, Sociology and Social Communication Theory, Dobroljubov State Linguistics University of Nizhny Novgorod (31a Minina St, Nizhny Novgorod, Russia,603155); savrutsk@mail.ru)

USTINKIN Sergei Vasil'evich, Dr.Sci.(Hist.), Professor; Dean of the Faculty of International Relations, Economy and Management, Professor of the Chair of International Relations and Political Science, Dobroljubov State Linguistics University of Nizhny Novgorod (31a Minina St, Nizhny Novgorod, Russia, 603155); Director of Volga branch of the Federal Center of Theoretical and Applied Sociology, Russian Academy of Sciences (4 Holodnyi Lane, Nizhny Novgorod, Russia, 603000; sv.ustinkin@gmail.com)

SEMENOV Dmitry Vladimirovich, Cand.Sci.(Philos.), Associate Professor; Associate Professor of the Chair of Philosophy, Sociology and Social Communication Theory, Dobroljubov State Linguistics University of Nizhny Novgorod (31a Minina St, Nizhny Novgorod, Russia, 603155); ds7771@bk.ru)

\section{THE INFLUENCE OF FAMILY AND INSTITUTES OF EDUCATION ON THE FORMATION OF THE YOUTH VALUE CONSCIOUSNESS}

Abstract. The article addresses some of timely issues of the influence of family and educational institutes on the formation of youth value orientations. In the context of the Russian Federation National Security Strategy the authors analyze the main

\footnotetext{
1 Федеральный проект «Крепкая семья». Доступ: https://proekty.er.ru/node/6600 (проверено 01.10.2018).
} 
characteristics of dynamics of students' assessing attitudes, forming in a new context of civilizational social development, determined by the processes of globalization, new information and communication technology, and the virtualization of the modern communicative space.

Keywords: system of education, family, national security, globalization, information and communication technology, value consciousness, value orientations, youth, virtual reality

ЕЖОВ Дмитрий Александрович - кандидат политических наук, доцент, старший научный сотрудник Центра политологических исследований Департамента политологии и массовых коммуникаций Финансового университета при Правительстве РФ (125993, Россия, г. Москва, Ленинградский np-кm, d. 49; president@lenta.ru)

\section{ДОСТОВЕРНОСТЬ ОСВЕЩЕНИЯ ПОЛИТИЧЕСКОЙ СИТУАЦИИ В РОССИИ СОВРЕМЕННЫМИ СМИ В ВОСПРИЯТИИ СТУДЕНЧЕСКОЙ МОЛОДЕЖИ}

Аннотация. В статье предлагается анализ результатов всероссийского опроса, проведенного в рамках изучения социально-политических настроений студенческой молодежи. Внимание автора концентрируется на проблеме оценки достоверности освещения политических событий современными СМИ в восприятии молодежного сегмента аудитории. Оценивается уровень достоверности информации, распространяемой посредством телевидения и глобальной сети Интернет.

Ключевые слова: политическая ситуация, средства массовой информации, студенческая молодежь, телевидение, Интернет

$\mathrm{M}$ ногообразие источников получения информации, вызванное развитием интернет-технологий и средств массовой коммуникации, предопределяет актуальность постановки вопроса о степени достоверности ретранслируемого политического контента. Не оспаривая доминанту субъективизма в восприятии соответствующих сведений, мы считаем вполне очевидным факт его дифференцированного отображения в различных социовозрастных группах. Особое значение среди последних имеет сегмент студенческой молодежи, ограничивающийся возрастными рамками от 18 до 24 лет, ввиду особенностей усвоения его представителями норм политической культуры. Дальнейшие авторские суждения основаны на результатах всероссийского опроса, проведенного Финансовым университетом при Правительстве РФ в 2018 г. по репрезентативной выборке в рамках осуществления научно-исследовательской работы, направленной на изучение социально-политических предпочтений студенческой молодежи.

Результаты всероссийского опроса во многом подтверждают распространенное мнение, основанное на восприятии молодежного сегмента социума как ярчайших представителей круга активных пользователей глобальной сети Интернет и потребителей распространяемых ею информационных продуктов. Так, в ходе проведенного исследования на вопрос: «Какими медиаресурсами Вы пользуетесь?» - 58,75\% предпочли ответить «Интернетом», и 33,17\% респондентов выбрали ответ «телевидение». Для полноты картины приведем данные, свидетельствующие, что радио предпочитают $1,75 \%$ опрошенных; печатную прессу - 0,42\%, всеми доступными источниками пользуются 5,17\%; а 0,75\% 